\title{
Association of Plasma Thrombin-Antithrombin Complex and Ischemic Stroke: A Systematic Review and Meta-analysis
}

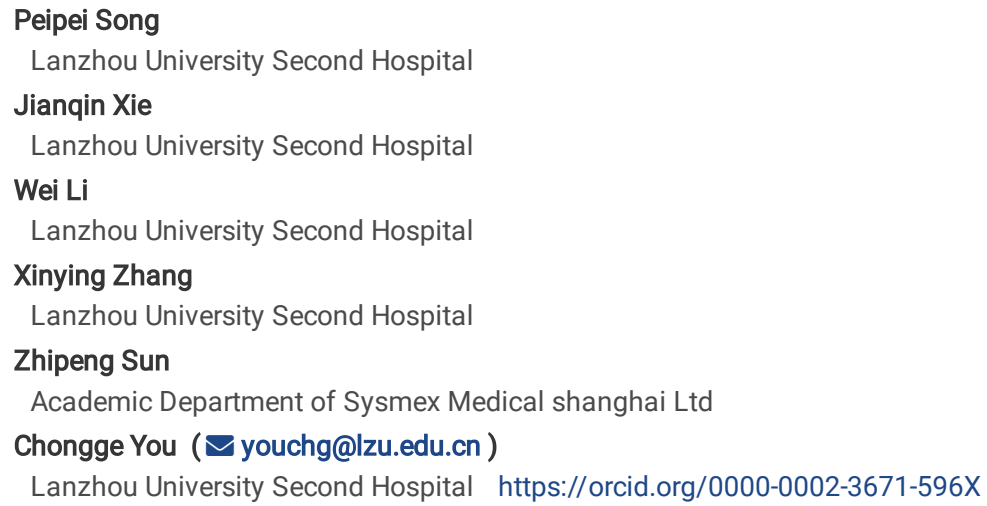

Research

Keywords: ischemic stroke, prognosis, stroke severity, thrombin-antithrombin complex

Posted Date: November 19th, 2021

DOI: https://doi.org/10.21203/rs.3.rs-1073053/v1

License: (c) (1) This work is licensed under a Creative Commons Attribution 4.0 International License. Read Full License 


\section{Abstract}

\section{Background and objective}

Thrombin-antithrombin complex (TAT) is a prethrombotic marker, and its application in ischemic stroke is still uncertain. The purpose of this systematic review and meta-analysis is to evaluate the relationship between plasma TAT and ischemic stroke base on the current evidence.

\section{Methods}

A systematic literature search was conducted for searching the relative studies that investigated the association of TAT and ischemic stroke in PubMed, EMBASE, and Cochrane library databases. Mean difference and $95 \%$ confidence interval as the effect sizes were synthesized by random effects model in Review Manager (RevMan) Version 5.4. Then, the heterogeneity was investigated using the Chi-square test and the possible sources of heterogeneity were explored by sensitivity analysis. The publication bias was estimated through Begg's and Egger's tests.

\section{Results}

A total of 12 eligible studies were included involving 1431 stroke cases and 532 healthy controls, of which six studies were eventually included in the metaanalysis. Plasma TAT in patients with ischemic stroke was significantly higher than that in healthy controls $(\mathrm{MD} 5.31,95 \% \mathrm{Cl}=4.12-6.51, \mathrm{P}<0.0001, P=97.8 \%)$. There is a difference of TAT level in the same period among cardioembolic, lacunar and atherothrombotic stroke (all $P<0.0001)$, in which the cardioembolic stroke with the highest level. Meanwhile, it is significant of TAT levels among various phases of cardioembolic stroke and the acute phase are markedly elevated (MD 7.75, 95Cl\%, 6.07-9.43, $\mathrm{P}<0.001)$. However, no difference was found in the atherothrombotic $(P=0.13)$ and lacunar stroke $(P=0.34)$. Besides, the higher TAT level is closely related to the poor prognosis of patients with ischemic stroke, including higher recurrence, mortality, unfavorable recovery (modified Rankin scale $>2$ ), and poor revascularization.

\section{Conclusions}

This study suggested that plasma TAT levels are different in ischemic stroke subtypes, which are closely associated with the progression and might have an effect on the prognosis.

PROSPERO CRD: 42021248787

\section{Introduction}

Stroke has become a serious threat to human health since it is one of the causes that lead to permanent disability and death worldwide [1]. More than 795,000 patients suffer from stroke and about 140,000 ones died every year in the United States (https://www.cdc.gov/stroke/facts.htm) [2]. Ischemic stroke accounts for $87 \%$ of total strokes and is the main focus of current stroke researches [3]. However, early diagnosis and effective prediction of ischemic stroke is difficult, so it is necessary to explore biomarkers with practical significance.

Ischemic brain damage involves the activation of a series of detrimental signaling cascades. Clinical guidelines suggest that thrombolysis is the most important method in the emergency department under the instruction of multi-mode computed tomography (CT) or magnetic resonance imaging (MRI) neuroimaging [4]. However, the treatment of intravenous thrombolysis with recombinant tissue thrombolytic plasminogen activator (rt-PA) window-time is very narrow, usually within 3.0-4.5 hours after the onset of neurologic symptoms, which delays the diagnostic time for visible neuroimaging techniques [5, 6]. On the other hand, it is difficult to distinguish ischemic stroke subtypes from these similar focal neurological deficits, such as complex migraine, demyelinating diseases, metabolic and vascular diseases [7]. In addition, the utility of advanced MRI technology current is limited because of lacking available emergency services or vascular neurologists [8]. Therefore, it is essential to find some simple biomarkers that can distinguish ischemic stroke subtypes.

Research on some easily available blood markers in ischemic stroke has been reported in a previous review for the diagnosis and differentiation of stroke, including matrix metalloproteinase-9, brain natriuretic peptide, and D-dimer [9]. Situ thrombosis and thromboembolism are the main causes of blood circulation blockage in ischemic stroke, which involve disorders of the coagulation system. When thrombin is formed, it will connect with antithrombin III (ATIII) and produces the thrombin-antithrombin (TAT) complex. TAT is considered to be a biomarker in the early stages of coagulation activation, which means thrombin formation and entering the prethrombotic state.

Elevated TAT has been proven to be associated with several diseases. There is clear evidence that patients with myocardial infarction were accompanied by mild inflammation with an increase in TAT [10]. The activity of TAT could identify patients with ongoing severe coagulopathy early in the course of sepsis [11]. Determination of the plasma TAT complex concentration is helpful for the evaluation of the prognostic severity of post-ICH brain injury [12]. However, to our knowledge, there are few reports on the comprehensive analysis of TAT in patients with ischemic stroke, and the association of TAT and the stage or subtypes of the disease are unclear. In addition, ischemic stroke is a dynamic process, in which different degrees of activation of coagulation exist in the various phases associated with distinct biological substrates molecular [13]. Hence, defining the ideal blood biomarker is of clinical importance for precision medicine in deciding stroke-type specific treatment.

Therefore, to pool the expression results of TAT in previous studies, we performed a systematic review and meta-analysis to clarify whether there are differences exist in various ischemic stroke subtypes and stages by reviewing the literature. Besides, we will seek to explain the relationship between TAT levels and prognosis reported in the patient groups for helping reducing mortality and better beyond hospital admission management. 


\section{Methods}

We performed this systematic review and meta-analysis according to the Preferred Reporting Items for Systematic Reviews and Meta-Analyses (PRISMA) [14]. The protocol of this study has been registered in the International Prospective Register of Systematic Reviews (PROSPERO CRD: 42021248787).

\section{Literature search}

A comprehensive search was conducted by two researchers (Peipei Song and Jianqin Xie) to search eligible studies from inception to October 13,2021 , in PubMed, EMBASE, Cochrane Library and Google Scholar. The combination of MeSH and free text terms were used to search in the databases and the strategy of PubMed as follow: ("antithrombins" OR "thrombate III" OR "AT III-protease complex") AND ("stroke" OR "cerebral infarction" OR "cerebrovascular accident"). The search results were limited to human studies that were written in English, and we also manually searched the references of original articles and reviews. Two authors independently completed the process of literature search and any indistinguishable records were conducted by negotiating with the third author (Wei Li). We showed the detailed search strategies for the databases in Supplementary Table 1.

\section{Inclusion and exclusion criteria}

All studies met the following inclusion criteria and were selected into our systematic review and meta-analysis based: (1) case-control study or cohort study, (2) study investigated the association of plasma TAT levels and strokes, (3) study including stroke subtypes or stages, (4) plasma TAT as one of the outcome indicators was reported in prognosis, (5) if the studies with the same case materials and published by the same authors, only the lasted or largest population will be included.

The studies were excluded in which they meet the following exclusion criteria: (1) repeated publications, (2) reviews or summaries, (3) non-human studies, (4) incomplete data or low quality in the research, and (5) studies measuring TAT level in cerebrospinal fluid or urine.

\section{Definition of subgroups}

Cardioembolic, lacunar and atherothrombotic stroke subjects were divided based on the findings of the clinical ancillary examination, such as cerebral angiography, ultrasound examination of carotid vessels, confirmation of the intracardiac embolization and the evdence of imageological diagnosis. We defined the acute phase ( $<24 \mathrm{~h})$, subacute phase (24-48h) and chronic phase ( $>7$ days) as the records. Another subgroup was determined according to the methods of TAT measurement.

\section{Data extracted and assessment of the quality}

Two authors (Wei Li and Xinying Zhang) independently completed the data extraction and quality assessment. For any indistinguishable record by consulting or talking over the corresponding author. We read the full text for extracting data and further assessment. The baseline characteristics of the literature were extracted by using the well-designed form. The Newcastle-Ottawa Scale (NOS) scale was used to assess the methodological quality of those included casecontrol or cohort studies [15]. Each of the literature is scored based on eight questions in three main broad categories: (1) patient selection; (2) comparability of study groups; (3) assessment of exposure. The total score (TS) is $9, T S \leq 5,6 \leq T S \leq 7$, and TS $\geq 8$ was regarded as low, moderate, and high quality respectively.

\section{Statistical analysis}

StataMP version 16 software is used to synthesize the study data, and $\mathrm{P}<0.05$ is considered to be statistically significant. We calculated the means and standard deviations in line with the method developed by Hozo et al [16] if the article provided the medians and ranges instead of the means and standard deviations. Mean difference (MD) was calculated as a summary statistic in the Random-effects model (Mantel-Haenszel test). The statistical heterogeneity was considered when $\mathrm{P} \leq 0.05$ in comparison among groups or $\mathrm{P}<0.1$ in comparison within groups. Chi-square test was used to assess the heterogeneity among the included studies, and quantified by the Higgin's $R$ statistic, $R<50 \%, 50 \% \leq R \leq 75 \%$, and $R>75 \%$ was regarded as low, moderate, and high heterogeneity, respectively. Subsequently, a sensitivity analysis was performed, in which one study at a time was removed and the others analyzed to estimate whether the results could have been affected markedly by a single study. Subgroup analysis was performed according to the different subtypes and phases of ischemic stroke. Begg's and Egger's regression tests were used to estimating the publication bias.

\section{Results}

\section{Characteristics of Included Studies}

After retrieving relevant search terms in PubMed, EMBASE and Cochrane Library databases, a total of 2406 publications were researched, and 4 articles were retrieved from Google Scholar. The PRISMA flow diagram for study inclusion in our meta-analysis was depicted in Fig 1.1651 articles remaining after deduplication, and then the letters, reviews, cases reported, animal studies, and literature not related to the topic were excluded by browsing the titles and abstracts, totaling 759 publications. A full-text of 538 potentially eligible articles was retrieved, studies were excluded again for no relation with TAT (379), study topic is not a stroke (138), and without full text (9). Finally, 12 studies were included in our meta-analysis.

A total of ten case-control studies and two cohort studies were incorporated into the systematic review and meta-analysis, including 1431 stroke cases and 532 healthy controls. Six studies were from Japan [17-22], two studies were from China [8, 23], and the remaining four were from Canada [24], the United States [25], Spain [26], and Finland [27]. The average ranges from 64.7 to 72.4 years old in the case group and 61 to 72.4 in the control. Computed tomography (CT) and/or magnetic resonance imaging (MRI) are the methods used in all studies to confirm the diagnosis. Serum TAT level were measured by enzyme- 
linked immunosorbent assay kits (ELISA) in nine studies, two studies used enzyme immunoassays to determine the biomarker, and only one study was detected by chemiluminescence. Six of the studies conducted follow-up records ( 1 month to 3 years) and reported the cut-off of TAT, three of which explained the OR between TAT and adverse outcome. Table 1 summarizes the characteristics of included studies, and the follow-up results are shown in Table 2 .

\section{Quality of included studies}

All studies were assessed for methodological quality by the Newcastle-Ottawa Scale (NOS). The range of quality scores is 7 to 8 for case-control, with a median of 7.5 (7.5 \pm 0.53 ) (Supplementary Table 2). All studies reported the case and control definition, comparability, ascertainment of exposure, and the same method of ascertainment for cases. But five of them do not report the source of the control group [17-19, 21, 22]. All the researches included a certain hospital or institution for a continuous-time, which we believe to be representativeness of the cases. However, no study describes the non-response rate. The quality scores of the two cohort studies were 6 [26] and 7 [25] respectively, both neither described comparability and non-exposed cohort and one of which has no statement about adequacy of follow up of cohort [26].

\section{Correlations between plasma TAT levels and ischemic stroke}

Ten studies investigated the association between plasma TAT levels and ischemic stroke. The result revealed that plasma TAT level was significantly higher in ischemic patients than those in healthy controls (MD 5.31, 95\% Cl =4.12-6.51, $\left.\mathrm{P}<0.0001, R=97.8 \%, \mathrm{P}_{\text {heterogeneity }}<0.00001, \mathrm{Fig} 2\right)$.

\section{Subgroup analysis of ischemic stroke}

We conducted a subgroup analysis to explore the distinction in the same period among cardioembolic, lacunar and atherothrombotic stroke, and the results are shown in Fig 3-5. The plasma TAT level in the three subgroups of ischemic stroke was significantly higher than control in the acute phase (MD 5.45, 95Cl\%, 3.97-6.93, $\mathrm{P}<0.001$, Fig 3). Similarly, the ischemic stroke subgroup with higher TAT level than control in subacute phases (MD 4.40, 95Cl\%, 3.01-5.78, $\mathrm{P}<0.001$, Fig 4), and chronic phase (MD 2.21, 95Cl\%, 1.50-2.93, P<0.001, Fig 5). During the same period, the plasma TAT level of cardioembolic stroke is the highest, followed by atherosclerosis and lacunar stroke.

Meanwhile, we analyzed the differences among different periods in each subtype of ischemic stroke. For cardioembolic stroke, it is significant among the acute, subacute and chronic phases (MD 7.75, 95Cl\%, 6.07-9.43, $\mathrm{P}<0.001$, supplementary Fig 1). Although there is no difference in atherothrombotic stroke (MD 3.26, 95Cl\%, 2.02-4.50, P=0.13, supplementary Fig 2), the plasma TAT level was marked elevated in the acute than that in the subacute and chronic phases. Besides, no significant difference was found in the lacunar stroke (MD 1.22, 95Cl\%, 0.79-1.65, P=0.34, $P=97.86 \%$, supplementary Fig 3 ), and the highest plasma TAT level is the subacute phase.

\section{The relationship between TAT and prognostic outcome}

A total of six studies have reported the relationship between plasma TAT level and prognosis of ischemic stroke prognosis (Table 2). We conducted the systematic review because the available data did not further perform synthesis. Three studies recorded recurrence of stroke, the incidence of short-term recurrence was $33 \%$, which was associated with a mean TAT concentration of $9.6 \mathrm{ng} / \mathrm{mL}[17,24,27$ ]. David Tanne et al [25] found that the baseline TAT level is related to the three-month mortality when it is more than $11.2 \mathrm{ng} / \mathrm{mL}(\mathrm{OR}=1.72,95 \% \mathrm{Cl}: 1.26-2.34)$. Similarly, the study of Israel Fernandez et al [23] indicates that there was a significant correlation between higher TAT levels and unfavorable function outcome (poor outcome modified Rankin scale $>2$ ) (OR=1.283, 95\% Cl: 1.105-1.489). On the contrary, lower plasma TAT levels in patients with ischemic stroke could be associated with a high success rate of revascularization $(\mathrm{OR}=2.7,95 \% \mathrm{Cl}: 1.2-6.1)$ [26].

\section{Sensitivity analysis and publication bias}

Sensitivity analysis was performed through the elimination method in which one study is deleted at a time to recalculated the combined estimate on remaining studies. However, the results showed that excluding any one study will not affect the results, this analysis confirmed the stability of results. Another subgroup analysis was performed to explore the source of heterogeneity based on the TAT detection method. There was no significant difference between the groups ( $P=0.11$, supplementary Fig 4). No publication bias between cases and control groups was estimated by Begg's $(P=0.4524)$ and Egger's ( $P=0.7787)$ regression test.

\section{Discussion}

This systematic review and meta-analysis analyzed the relationship between plasma TAT and ischemic stroke. The results showed that there is a higher level of TAT in the ischemic stroke group than healthy control. Meantime, the plasma TAT level will liner decrease with the extension of ischemic time, and with the highest in the acute phase. Compare with atherothrombotic and lacunar stroke, the higher concentration of TAT was found in cardioembolic stroke. The result of this systematic review showed that plasma TAT was closely related to the subsequent prognosis.

The increasing occurrence of ischemic stroke was reported in recent years as the population ages[28]. Although recent clinical trials have shown that there are many opportunities to improve stroke prevention strategies and effectively intervene in acute strokes, there are still challenges in early and rapid diagnosis. CT or MRI are commonly used in clinical diagnosis at current, but the confirmation time of lesions far exceeds the optimal treatment period. For patients admitted within four hours were applied in thrombolytic therapy recommended by clinical guidelines, which is an effective treatment[6]. Besides, no specific markers have been found that can be used for the early diagnosis of ischemic stroke. The essence of ischemic stroke is a thrombotic disease caused by endothelial injury, hypercoagulation, or blood flow disorder. Thrombus can be classified into thromboembolism and thrombosis according to the different sources of embolus. Therefore, ischemic stroke main included atherosclerotic and cardioembolic stroke, which are caused by thrombosis and thromboembolism, 
respectively. Another lacunar stroke is also called asymptomatic cerebral infarction, usually a small blood vessel obstruction of no more than $1.5 \mathrm{~cm}$ in diameter [29]. TAT is a complex of thrombin and antithrombin, most circulating TAT derives from the process of thrombosis caused by endothelial cell injury. TAT can be detected in thrombus-related diseases since it indicates the activation of thrombin which contributes to thrombus generation [30]. Hence, it is meaningful to find biomarkers with diagnostic value.

In our study, the results demonstrated that patients with cardioembolic stroke have higher TAT levels than those with atherothrombotic strokes, which suggested that TAT might be able to differentiate cardioembolic stroke from atherothrombotic $(P=0.006)$. Similar to our result, Song, $J$ et al. proved that cardioembolic stroke might be severer and with higher TAT levels than other stroke subtypes [31]. The TAT in subtypes of ischemic stroke differs depending on the underlying mechanism of embolus formation. Thrombosis in the coronary artery or heart cavity caused by rupture or fissuring of plaques or damages of the heart structure will flow and block the cerebral vessels, especially in atrial fibrillation [32]. Besides, compared with cerebrovascular, plentiful large clotting factors were activated in the heart blood vessel, more blood cells are recruited and a large amount of fibrinogen is activated, then thrombi are formed. Some studies have shown that the difference between stroke thrombus and acute myocardial infarction thrombus lies in the abundance of platelets and fibrin and the increase in the number of inflammatory cells per thrombus area [33,34]. However, in atherosclerotic stroke, the plaques that are most prone to rupture with a rich lipid core and thin fibrous cap, inflammatory cells accumulate at the site of endothelial destruction are the main driving factor for the growth of early pale thrombus. There have been a few studies reporting patients with carotid atherosclerosis did have a better functional outcome than patients with cardioembolism [35].

The previous studies have investigated the association between TAT and acute myocardial infarction (AMI), which showed that the highest TAT level is at the subacute phase for those patients with myocardial infarction $[10,36]$. However, a higher TAT level in the acute phase of ischemic stroke was found in our result, which might be related to the mechanism of thrombus formation in the different diseases. This is most commonly due to thrombus formation in a coronary artery [34]. The present findings demonstrated different sequential alterations in thrombotic markers following three subtypes of brain infarct [37]. Thrombosis in large blood vessels is not easy to detect in the early stage, and there are usually some confusing signs before the occurrence of acute myocardial infarction, such as arrhythmia and angina pectoris. TAT levels in the subacute phase may also be affected by mechanical treatment, more thrombin production induced by the stimulation of endothelial injury. However, no matter thrombosis or thromboembolism, the cerebral blood flow will be blocked instantly in patients with cerebral infarction, leading to hypoperfusion and clinical symptoms. In addition, asymptomatic focal small cerebral vascular embolism is also common in ischemic strokes, such as lacunar infarction.

Several published systematic reviews have generated a shred of evidence regarding the role of biomarkers in ischemic stroke. Yan $\mathrm{H}$ et al. investigated the correlations of TM and hs-CRP with ischemic stroke [38]. A large number of articles have reported the D-dimer and its application in ischemic stroke [39], which is generally regarded as an indicator for evaluating thrombosis. In our study, the higher plasma TAT level was found in the subtype of the cardioembolic and acute phases. Besides, we found that higher TAT levels often indicate higher recurrence [27], worse functional recovery [23], and higher mortality [25]. Lower plasma TAT levels in ischemic stroke patients with thrombolytic tPA or mechanical recanalization therapies were more beneficial to successful vascular recanalization, which may be related to the activity of thrombin and the loose thrombus structure [26, 40]. Though plasma TAT showed the clinical value as an auxiliary factor to identify ischemic stroke subtypes and phases, it still needs to be verified in large-scale research.

The study of comprehensive biomarkers in the stages of ischemic stroke is still in its infancy [41]. The changes of coagulation biomarkers may precede the imaging manifestations of clinical symptoms. Although our study showed the plasm TAT was beneficial for ischemic stroke, the specificity of TAT needs to be verified in other prethrombotic diseases. These biomarkers are unlikely to replace imaging tests as a first-line diagnostic tool for the detection of ischemic stroke, but they may be a strategy to reduce the cost of screening and as a mechanistic pathway aimed at new treatments. Use a combination of cheaper and high-sensitivity diagnostic tests, such as TAT and D-dimer, as the initial stage detection and followed by MRI tests. For developing countries especially where neuroimaging facilities are limited, or in settings where the brain imaging is normal, the use of blood biomarkers at the point of care in combination with the clinical predictors could be an effective alternative for rapid diagnosis of ischemic stroke in the future.

\section{Limitation}

We acknowledge limitations in our study. First of all, the number of studies included in our meta-analysis is small, and there are large differences in sample sizes, which may have an impact on statistical analysis and become another source of heterogeneity. Secondly, manual search for relevant reviews may lead to omissions in the literature, which may potentially affect the validity of our results. Finally, due to the lack of research data, the relationship between the severity of ischemic stroke based on the NIHSS scores and TAT has not been analyzed in this meta-analysis, which may be a part worth exploring in the future. Choosing English language articles only is also one of our shortcomings.

\section{Conclusion}

Our meta-analysis results showed an important relationship between plasma TAT levels and ischemic stroke, and plasma TAT might be involved in the progression and prognosis of ischemic stroke, and it also aids in identifying stroke subtypes.

\section{Declarations}

\section{Acknowledgment}

Thanks to Professor Jinhui Tian (Evidence-Based Medicine Center, School of BasicMedical Sciences, Lanzhou University) for his kind guidance in literature research, data analysis and manuscript writing. 


\section{Author Contributions}

Chongge You designed this study; Peipei Song and Jianqin Xie performed the search strategy; Wei Li and Xinying Zhang collected data; Zhipeng Sun rechecked data and performed the analysis; Peipei Song assessed the quality of studies and wrote the manuscript, Jianqin Xie, Wei Li, Xinying Zhang, Zhipeng Sun and Chongge You edited. All listed authors reviewed and revised the manuscript.

\section{Funding}

This work was supported by Special Fund Project for Ph.D. Candidate Training of the Hospital (grant no. YJS-BD-23), Cuiying Scientific and Technological Innovation Program of Lanzhou University Second Hospital (grant no. CY2020-MS18), and Science and Technology Plan Project of Lanzhou (grant no. 2019ZD-67)

\section{Availability of data and materials}

There is no data applicable to the current protocol. The data extracted and analysed in the prospective review will be made available from the corresponding author on request.

\section{Ethics approval and consent to participate}

Not applicable

\section{Consent for publication}

Not applicable

\section{Competing interests}

The authors declare they have no competing interests

\section{References}

1. M Dichgans, S L PulitJ Rosand.Stroke genetics: discovery, biology, and clinical applications. The Lancet. Neurology.2019; 18(6):587-599.

2. Stroke Facts | cdc.gov. 2017. 2017-09-06T08:10:23Z; Available from: https://www.cdc.gov/stroke/facts.htm.

3. D BarthelsH Das.Current advances in ischemic stroke research and therapies. Biochim Biophys Acta Mol Basis Dis.2020; 1866(4):165260.

4. J M Wardlaw, A J Farrall, D Perry, R von Kummer, O Mielke, T Moulin, A CicconeM Hill.Factors influencing the detection of early CT signs of cerebral ischemia: an internet-based, international multiobserver study. Stroke.2007; 38(4):1250-6.

5. R Morihara, S Kono, K Sato, N Hishikawa, Y Ohta, T Yamashita, K Deguchi, Y Manabe et al.Thrombolysis with Low-Dose Tissue Plasminogen Activator 34.5 h After Acute Ischemic Stroke in Five Hospital Groups in Japan. Transl Stroke Res.2016; 7(2):111-9.

6. T van Seeters, G J Biessels, L J Kappelle, I C van der Schaaf, J W Dankbaar, A D Horsch, J M Niesten, M J Luitse et al.The Prognostic Value of CT Angiography and CT Perfusion in Acute Ischemic Stroke. Cerebrovasc Dis.2015; 40(5-6):258-69.

7. V Misra, H Fadil, R Hoque, U Menon, E Gonzalez-ToledoS Jaffe.Clinically presenting acute/subacute ischemic stroke: differential diagnosis of the nonenhanced CT hypodensity by advanced neuroimaging. Neurol Res.2009; 31(8):816-23.

8. R Meng, Z Y Li, X Ji, Y Ding, S MengX Wang.Antithrombin III associated with fibrinogen predicts the risk of cerebral ischemic stroke. Clin Neurol Neurosurg.2011; 113(5):380-6.

9. S Misra, J Montaner, L Ramiro, R Arora, P Talwar, M Nath, A Kumar, P Kumar et al.Blood biomarkers for the diagnosis and differentiation of stroke: A systematic review and meta-analysis. Int J Stroke.2020; 15(7):704-721.

10. E Réganon, V Vila, V Martínez-Sales, A VayaJ Aznar.Inflammation, fibrinogen and thrombin generation in patients with previous myocardial infarction. Haematologica.2002; 87(7):740-5; discussion 745.

11. K Koyama, S Madoiwa, S Nunomiya, T Koinuma, M Wada, A Sakata, T Ohmori, J Mimuro et al.Combination of thrombin-antithrombin complex, plasminogen activator inhibitor-1, and protein $\mathrm{C}$ activity for early identification of severe coagulopathy in initial phase of sepsis: a prospective observational study. Crit Care.2014; 18(1):R13.

12. C H Wu, R L Yang, S Y Huang, H Z Li, K Y Wang, D H Yang, X H Yan, X H Xue et al.Analysis of thrombin-antithrombin complex contents in plasma and hematoma fluid of hypertensive intracerebral hemorrhage patients after clot removal. Eur J Neurol.2011; 18(8):1060-6.

13. S Bernardo-Castro, J A Sousa, A Brás, C Cecília, B Rodrigues, L Almendra, C Machado, G Santo et al.Pathophysiology of Blood-Brain Barrier Permeability Throughout the Different Stages of Ischemic Stroke and Its Implication on Hemorrhagic Transformation and Recovery. Front Neurol.2020; 11594672.

14. D Moher, A Liberati, J TetzlaffD G Altman.Preferred reporting items for systematic reviews and meta-analyses: the PRISMA statement. Ann Intern Med.2009; 151(4):264-9, w64.

15. A Stang.Critical evaluation of the Newcastle-Ottawa scale for the assessment of the quality of nonrandomized studies in meta-analyses. Eur $\mathrm{J}$ Epidemiol.2010; 25(9):603-5.

16. S P Hozo, B Djulbegovicl Hozo.Estimating the mean and variance from the median, range, and the size of a sample. BMC Med Res Methodol.2005; 513.

17. K Takano, T Yamaguchi, H KatoT Omae.Activation of coagulation in acute cardioembolic stroke. Stroke.1991; 22(1):12-16. 
18. S Kataoka, G Hirose, A Hori, T ShirakawaT Saigan.Activation of thrombosis and fibrinolysis following brain infarction. J Neurol Sci.2000; 181(1-2):82-8.

19. M Yamazaki, S UchiyamaS Maruyama.Alterations of haemostatic markers in various subtypes and phases of stroke. Blood Coagul Fibrinolysis.1993; 4(5):707-12.

20. N K Ono, T. Suehiro, A. Oku, K. I. Fujikake, K. Kakishita, E.Clinical significance of new coagulation and fibrinolytic markers in ischemic stroke patients. Stroke.1991; 22(11):1369-1373.

21. M Nagayama, Y ShinoharaT Nagayama.Detection of prothrombotic state in ischemic stroke by monitoring plasma molecular markers. J Stroke Cerebrovasc Dis.1994; 4(4):250-4.

22. K Takano, T YamaguchiK Uchida.Markers of a hypercoagulable state following acute ischemic stroke. Stroke.1992; 23(2):194-8.

23. $\mathrm{N}$ Ye, Z Liu, X Wang, X XuW Wu.Evaluation of analytic and clinical performance of thrombin-antithrombin complex and D-dimer assay in prognosis of acute ischemic stroke. Blood Coagul Fibrinolysis.2020; 31(5):303-309.

24. E A Fon, A Mackey, R Côté, C Wolfson, D M Mcllraith, J LeclercF Bourque.Hemostatic markers in acute transient ischemic attacks. Stroke.1994; 25(2):282286.

25. D Tanne, R F Macko, Y Lin, B C TilleyS R Levine.Hemostatic activation and outcome after recombinant tissue plasminogen activator therapy for acute ischemic stroke. Stroke.2006; 37(7):1798-804.

26. I Fernandez-Cadenas, M Mendioroz, J Munuera, J Alvarez-Sabin, A Rovira, A Quiroga, N Corbeto, M Rubiera et al.Lower concentrations of thrombinantithrombin complex (TAT) correlate to higher recanalisation rates among ischaemic stroke patients treated with t-PA. Thromb Haemost.2009; 102(4):759-64.

27. E Haapaniemi, L Soinne, M Syrjälä, M KasteT Tatlisumak.Serial changes in fibrinolysis and coagulation activation markers in acute and convalescent phase of ischemic stroke. Acta Neurol Scand.2004; 110(4):242-7.

28. S PaulE Candelario-Jalil.Emerging neuroprotective strategies for the treatment of ischemic stroke: An overview of clinical and preclinical studies. Exp Neurol.2021; 335113518 .

29. J Vynckier, B Maamari, L Grunder, M B Goeldlin, T R Meinel, J Kaesmacher, A Hakim, M Arnold et al.Early Neurologic Deterioration in Lacunar Stroke: Clinical and Imaging Predictors and Association With Long-term Outcome. Neurology.2021;

30. A Bugatti, S Marsico, P Mazzuca, K Schulze, T Ebensen, C Giagulli, E Peña, L Badimón et al.Role of Autophagy in Von Willebrand Factor Secretion by Endothelial Cells and in the In Vivo Thrombin-Antithrombin Complex Formation Promoted by the HIV-1 Matrix Protein p17. Int J Mol Sci.2020; 21(6):

31. J W Song, K S Song, J R Choi, S Y KimJ H Rhee.Plasma level of IL-6 and its relationship to procoagulant and fibrinolytic markers in acute ischemic stroke. Yonsei Med J.2006; 47(2):201-6.

32. A Aliena-Valero, J Baixauli-Martín, G Torregrosa, J I TemblJ B Salom.Clot Composition Analysis as a Diagnostic Tool to Gain Insight into Ischemic Stroke Etiology: A Systematic Review. J Stroke.2021; 23(3):327-342.

33. M Koupenova, B E Kehrel, H A CorkreyJ E Freedman.Thrombosis and platelets: an update. Eur Heart J.2017; 38(11):785-791.

34. T Shibata, S Kawakami, T Noguchi, T Tanaka, Y Asaumi, T Kanaya, T Nagai, K Nakao et al.Prevalence, Clinical Features, and Prognosis of Acute Myocardial Infarction Attributable to Coronary Artery Embolism. Circulation.2015; 132(4):241-50.

35. M Zotter, E I Piechowiak, R Balasubramaniam, R Von Martial, K Genceviciute, M Blanquet, N Slavova, H Sarikaya et al.Endovascular therapy in patients with large vessel occlusion due to cardioembolism versus large-artery atherosclerosis. Therapeutic advances in neurological disorders.2021; $141756286421999017-1756286421999017$.

36. J Figueras, Y Monasterio, R M Lidón, E NietoJ Soler-Soler.Thrombin formation and fibrinolytic activity in patients with acute myocardial infarction or unstable angina: in-hospital course and relationship with recurrent angina at rest. J Am Coll Cardiol.2000; 36(7):2036-43.

37. W M Feinberg, D C Bruck, M A JeterJ J Corrigan.Fibrinolysis after acute ischemic stroke. Thrombosis research.1991; 64(1):117-127.

38. Y Han, S Wu, Q Hu, J Q Xiao, D M Wei, L L LiuZ Z Li.Thrombomodulin and High-Sensitive C-Reactive Protein Levels in Blood Correlate with the Development of Cerebral Infarction Among Asians. Mol Neurobiol.2016; 53(4):2659-67.

39. T Sato, S Sato, H Yamagami, T Komatsu, T Mizoguchi, T Yoshimoto, M Takagi, M lhara et al.D-dimer level and outcome of minor ischemic stroke with large vessel occlusion. J Neurol Sci.2020; 413116814.

40. J H RhaJ L Saver.The impact of recanalization on ischemic stroke outcome: a meta-analysis. Stroke.2007; 38(3):967-73.

41. A N Simpkins, M Janowski, H S Oz, J Roberts, G Bix, S DoréA M Stowe.Biomarker Application for Precision Medicine in Stroke. Transl Stroke Res.2020; 11(4):615-627.

\section{Tables}

Table 1 Characteristics of included studies in the systematic review meta-analysis 


\begin{tabular}{|c|c|c|c|c|c|c|c|c|c|c|}
\hline Studies & Patients & Country & $\begin{array}{l}\text { Confirmed } \\
\text { method }\end{array}$ & Cases & $\begin{array}{l}\text { Average } \\
\text { age }\end{array}$ & Control & $\begin{array}{l}\text { Average } \\
\text { age }\end{array}$ & Test time & $\begin{array}{l}\text { Test } \\
\text { method }\end{array}$ & $\begin{array}{l}\text { From first } \\
\text { onset to } \\
\text { hospital }\end{array}$ \\
\hline $\begin{array}{l}\text { KentaroTakano } \\
1991\end{array}$ & $\begin{array}{l}\text { acute } \\
\text { cardioembolic } \\
\text { stroke }\end{array}$ & Japan & 2D-echo, CT & 22 & 64.70 & 25 & 61.00 & $<24 h$ & ELISA & within $24 \mathrm{~h}$ \\
\hline $\begin{array}{l}\text { Ran Meng } \\
2011\end{array}$ & $\begin{array}{l}\text { cerebral } \\
\text { ischemic } \\
\text { stroke }\end{array}$ & China & $\begin{array}{l}\text { MRI/DWI/MRA } \\
\text { or CTA }\end{array}$ & 152 & 58.72 & 46 & 51.89 & $<24 h$ & ELISA & $\begin{array}{l}\text { within } 4.5 \\
\mathrm{~h}\end{array}$ \\
\hline Fon E A 1994 & $\begin{array}{l}\text { transient } \\
\text { ischemic } \\
\text { attack }(T I A)\end{array}$ & Canada & $\mathrm{CT}$ & 36 & 68.80 & 65 & 65.50 & $<7 d, 1$ mon, 3mon & ELISA & within $7 \mathrm{~d}$ \\
\hline $\begin{array}{l}\text { Ye Naifang } \\
2020\end{array}$ & $\begin{array}{l}\text { acute } \\
\text { ischemic } \\
\text { stroke }\end{array}$ & China & CT and/or MRI & 236 & 70.00 & 90 & 69.00 & $<12 h$ & $\begin{array}{l}\text { Chemilumi- } \\
\text { nescence }\end{array}$ & within $24 \mathrm{~h}$ \\
\hline $\begin{array}{l}\text { Israel } \\
\text { Fernandez } \\
\text { Cadenas } 2009\end{array}$ & $\begin{array}{l}\text { ischaemic } \\
\text { stroke }\end{array}$ & Spanish & $\mathrm{CT}$ and $\mathrm{MRI}$ & 89 & 72.40 & - & - & $\begin{array}{l}\text { admission, } 1 \mathrm{~h}, 2 \mathrm{~h} \text {, } \\
24 \mathrm{~h}, 48 \mathrm{~h} \text { after } \\
\text { post-tPA }\end{array}$ & ELISA & within $3 \mathrm{~h}$ \\
\hline $\begin{array}{l}\text { Haapaniemi E } \\
2004\end{array}$ & $\begin{array}{l}\text { ischemic } \\
\text { stroke }\end{array}$ & Finland & radiologically & 55 & 60.20 & 55 & 60.00 & $\begin{array}{l}\text { 2d, 7d, 1mon, } \\
3 \text { mon }\end{array}$ & ELISA & within $24 \mathrm{~h}$ \\
\hline $\begin{array}{l}\text { Satoshi } \\
\text { Kataoka } 2000\end{array}$ & $\begin{array}{l}\text { acute } \\
\text { brain } \\
\text { infarction }\end{array}$ & Japan & CT and MRI & 137 & 68.32 & 32 & 66.50 & $\begin{array}{l}\text { 48h, } 1 \text { week, } \\
3 \text { weeks }\end{array}$ & ELISA & within $48 \mathrm{~h}$ \\
\hline $\begin{array}{l}\text { Yamazaki M } \\
1993\end{array}$ & $\begin{array}{l}\text { cerebral } \\
\text { infarction }\end{array}$ & Japan & CT or MRI & 138 & 65.40 & 23 & 60.00 & $\begin{array}{l}\text { 7d,1mon, } \\
\text { and in } 1 \mathrm{mon}\end{array}$ & EIA & $\begin{array}{l}\text { no } \\
\text { description }\end{array}$ \\
\hline $\begin{array}{l}\text { Noriko } \\
\text { Ono1991 }\end{array}$ & $\begin{array}{l}\text { ischemic } \\
\text { stroke }\end{array}$ & Japan & CT and MRI & 98 & 69.50 & 50 & 66.00 & $<24 h$ & ELISA & within $5 \mathrm{~d}$ \\
\hline $\begin{array}{l}\text { Masao } \\
\text { Nagayama } \\
1994\end{array}$ & $\begin{array}{l}\text { ischemic } \\
\text { stroke }\end{array}$ & Japan & CT & 53 & 63.50 & 37 & 60.00 & $\begin{array}{l}\text { 48h, 3d, 7d, } \\
\text { 14d, 1mon }\end{array}$ & ELISA & within $3 \mathrm{~d}$ \\
\hline Takano K 1992 & $\begin{array}{l}\text { acute } \\
\text { ischemic } \\
\text { stroke }\end{array}$ & Japan & $\begin{array}{l}\text { CT and } \\
\text { cerebral } \\
\text { angiography }\end{array}$ & 54 & 66.00 & 20 & 61.60 & $48 \mathrm{~h}, 7 \mathrm{~d}, 1 \mathrm{mon}$ & ELISA & within $48 \mathrm{~h}$ \\
\hline $\begin{array}{l}\text { David Tanne } \\
2006\end{array}$ & $\begin{array}{l}\text { acute } \\
\text { ischemic } \\
\text { stroke }\end{array}$ & USA & $\mathrm{CT}$ & 361 & 68 & - & - & $\begin{array}{l}2 \mathrm{~h}, 24 \mathrm{~h}, 7-10 \mathrm{~d} \text {, } \\
\text { and } 3 \mathrm{mon}\end{array}$ & EIA & within $24 \mathrm{~h}$ \\
\hline
\end{tabular}

CT: Computed tomography; MRI: magnetic resonance imaging; 2D-echo: two-dimensional echocardiography; DWI: diffusion-weighted imaging; PWI: perfusionweighted imaging; ELISA: enzyme-linked immunosorbent assay; EIA: enzyme immunoassays

Table 2 The relationship between TAT and the outcome of ischemic stroke patients after a follow-up 


\begin{tabular}{|c|c|c|c|c|c|c|c|c|c|c|c|c|}
\hline Studies & Patients & Country & Cases & $\begin{array}{l}\text { Average } \\
\text { age }\end{array}$ & $\begin{array}{l}\text { From } \\
\text { the first } \\
\text { onset to } \\
\text { hospital }\end{array}$ & $\begin{array}{l}\text { Cut-off of } \\
\text { TAT }\end{array}$ & $\begin{array}{l}\text { Follow- } \\
\text { up time }\end{array}$ & $\begin{array}{l}\text { Recurrence } \\
\text { cases }\end{array}$ & Outcomes & OR & $95 \mathrm{Cl}$ & Tes \\
\hline $\begin{array}{l}\text { Takano K } \\
2000\end{array}$ & $\begin{array}{l}\text { acute } \\
\text { cardioembolic } \\
\text { stroke }\end{array}$ & Japan & 22 & 64.7 & $\begin{array}{l}\text { within } \\
24 \mathrm{~h}\end{array}$ & $12.1 \mathrm{ng} / \mathrm{mL}$ & $\begin{array}{l}2 \\
\text { months }\end{array}$ & 8 & recurrence & - & - & ELI \\
\hline $\begin{array}{l}\text { E A Fon } \\
1994\end{array}$ & $\begin{array}{l}\text { transient } \\
\text { ischemic } \\
\text { attack }(\mathrm{TIA})\end{array}$ & Canada & 36 & 68.8 & $\begin{array}{l}\text { within } 7 \\
\text { day }\end{array}$ & $7.8 \mathrm{ng} / \mathrm{mL}$ & $\begin{array}{l}13 \\
\text { months }\end{array}$ & 12 & recurrence & - & - & ELI \\
\hline $\begin{array}{l}\text { Haapaniemi } \\
\text { E. } 2004\end{array}$ & $\begin{array}{l}\text { ischemic } \\
\text { stroke }\end{array}$ & Finland & 55 & 60.2 & $\begin{array}{l}\text { within } \\
24 \mathrm{~h}\end{array}$ & 7.9ng/L & 3 years & 16 & recurrence & - & - & ELI \\
\hline $\begin{array}{l}\text { David } \\
\text { Tanne } 2006\end{array}$ & $\begin{array}{l}\text { acute } \\
\text { ischemic } \\
\text { stroke }\end{array}$ & USA & 361 & 68.0 & $\begin{array}{l}\text { within } \\
24 \mathrm{~h}\end{array}$ & $11.2 \mathrm{ng} / \mathrm{mL}$ & $\begin{array}{l}3 \\
\text { months }\end{array}$ & - & mortality & 1.72 & $\begin{array}{l}1.26- \\
2.34\end{array}$ & EIA \\
\hline $\begin{array}{l}\text { Ye Naifang } \\
2020\end{array}$ & $\begin{array}{l}\text { Acute } \\
\text { ischemic } \\
\text { stroke }\end{array}$ & China & 236 & 70.0 & $\begin{array}{l}\text { within } \\
24 \mathrm{~h}\end{array}$ & $6.03 \mathrm{ng} / \mathrm{mL}$ & $\begin{array}{l}1 \\
\text { months }\end{array}$ & 35 & $\begin{array}{l}\text { unfavorable } \\
\text { function }\end{array}$ & 1.283 & $\begin{array}{l}1.105- \\
1.489\end{array}$ & $\begin{array}{l}\text { Che } \\
\text { nes }\end{array}$ \\
\hline $\begin{array}{l}\text { Israel } \\
\text { Fernandez- } \\
\text { Cadenas } \\
2009\end{array}$ & $\begin{array}{l}\text { ischaemic } \\
\text { stroke }\end{array}$ & Spanish & 89 & 72.4 & $\begin{array}{l}\text { within } 3 \\
\mathrm{~h}\end{array}$ & $<24 \mu \mathrm{g} / \mathrm{L}$ & $\begin{array}{l}3 \\
\text { months }\end{array}$ & 16 & $\begin{array}{l}\text { Revascularis- } \\
\text { ation rates }\end{array}$ & 2.7 & $\begin{array}{l}1.2- \\
6.1\end{array}$ & ELI \\
\hline
\end{tabular}

ELISA: enzyme-linked immunosorbent assay; EIA: enzyme immunoassays

\section{Figures}

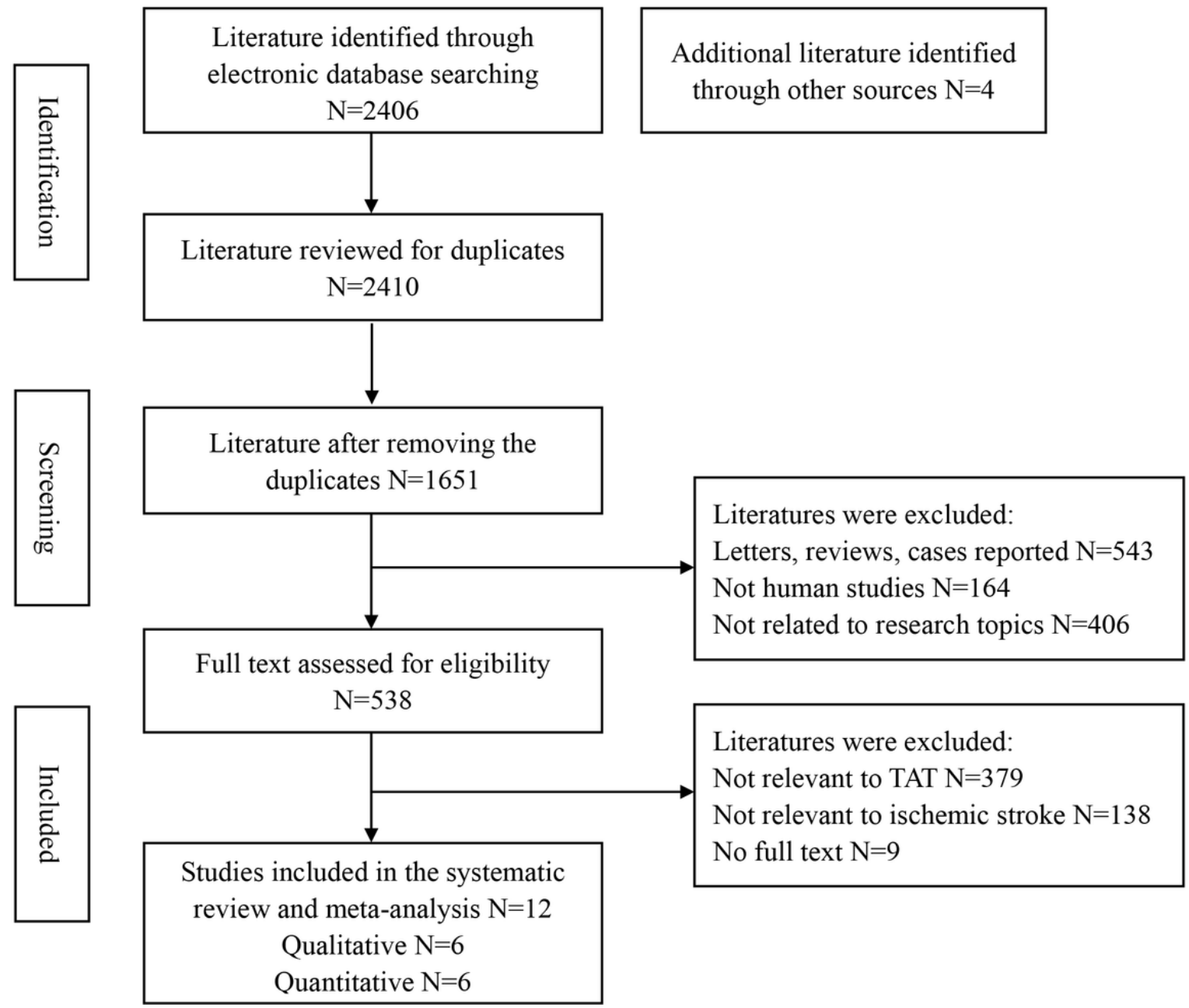

Figure 1

PRISMA flow diagram for the detailed procedures of study screening of systematic review and meta-analysis. 


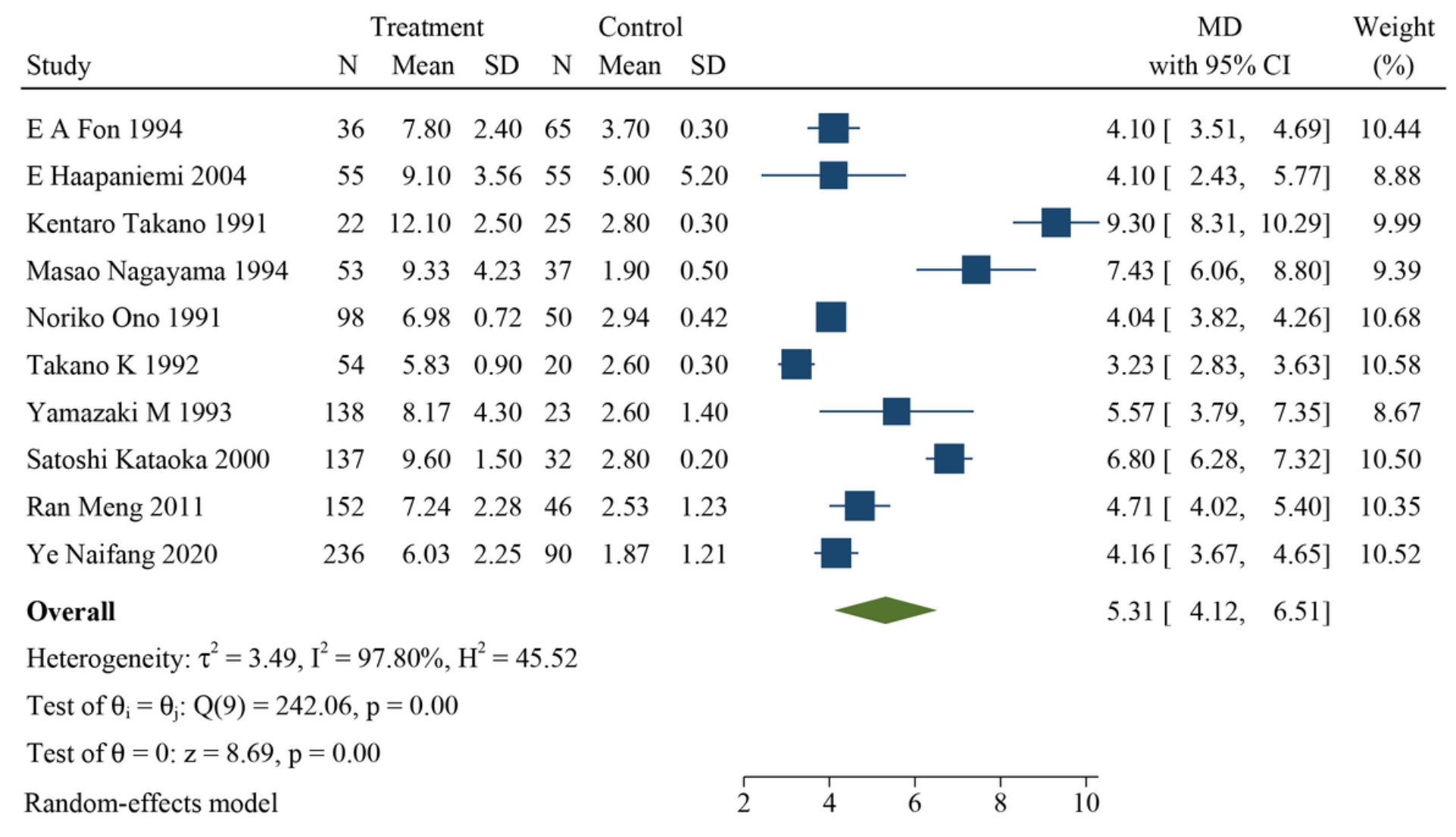

Figure 2

Plasma TAT levels in ischemic stroke and healthy control 


\begin{tabular}{|c|c|c|c|c|c|c|c|c|c|c|}
\hline \multirow[b]{2}{*}{ Study } & \multicolumn{3}{|c|}{ Treatment } & \multicolumn{3}{|c|}{ Control } & \multirow{2}{*}{\multicolumn{3}{|c|}{$\begin{array}{c}\text { MD } \\
\text { with } 95 \% \text { CI }\end{array}$}} & \multirow{2}{*}{$\begin{array}{c}\text { Weight } \\
(\%)\end{array}$} \\
\hline & $\mathrm{N}$ & Mean & $\mathrm{SD}$ & $\mathrm{N}$ & Mean & $\mathrm{SD}$ & & & & \\
\hline \multicolumn{11}{|l|}{ atherothrombotic stroke } \\
\hline Kentaro Takano 1992 & 10 & 4.3 & 0.7 & 20 & 2.6 & 0.3 & 1.70[ & 1.35 & $2.05]$ & 8.81 \\
\hline M Yamazaki 1993 & 32 & 5.4 & 3.9 & 23 & 2.6 & 1.4 & 2.80[ & 1.13 & $4.47]$ & 7.96 \\
\hline Masao Nagayama 1994 & 17 & 10.5 & 5.5 & 37 & 1.9 & 0.5 & 8.60[ & 6.83 & $10.37]$ & 7.87 \\
\hline SatoshiKataoka 2000 & 41 & 12.0 & 1.5 & 32 & 2.8 & 0.2 & 9.20[ & 8.68 & $9.72]$ & 8.76 \\
\hline \multicolumn{7}{|c|}{ Heterogeneity: $\tau^{2}=24.38, \mathrm{I}^{2}=99.47 \%, \mathrm{H}^{2}=188.86$} & 5.57[ & 0.69 & $10.45]$ & \\
\hline \multicolumn{11}{|c|}{ Test of $\theta_{\mathrm{i}}=\theta_{\mathrm{j}}: \mathrm{Q}(3)=566.59, \mathrm{p}=0.00$} \\
\hline \multicolumn{11}{|l|}{ cardioembolic stroke } \\
\hline Kentaro Takano 1992 & 21 & 10.2 & 1.9 & 20 & 2.6 & 0.3 & 7.60[ & 6.76 & $8.44]$ & 8.61 \\
\hline M Yamazaki 1993 & 52 & 16.0 & 7.2 & 23 & 2.6 & 1.4 & 13.40[ & 10.42 & $16.38]$ & 6.52 \\
\hline Masao Nagayama 1994 & 19 & 14.8 & 6.4 & 37 & 1.9 & 0.5 & 12.90[ & 10.84 & 14.96] & 7.57 \\
\hline SatoshiKataoka 2000 & 38 & 12.0 & 1.5 & 32 & 2.8 & 0.2 & 9.20[ & 8.68 & $9.72]$ & 8.76 \\
\hline \multicolumn{7}{|c|}{ Heterogeneity: $\tau^{2}=3.08, \mathrm{I}^{2}=91.00 \%, \mathrm{H}^{2}=11.11$} & 10.32[ & 8.41 & $12.24]$ & \\
\hline \multicolumn{11}{|c|}{ Test of $\theta_{i}=\theta_{j}: Q(3)=33.34, p=0.00$} \\
\hline \multicolumn{11}{|l|}{ lacunar stroke } \\
\hline Kentaro Takano 1992 & 23 & 3.0 & 0.2 & 20 & 2.6 & 0.3 & 0.40[ & 0.25 & $0.55]$ & 8.85 \\
\hline M Yamazaki 1993 & 54 & 3.1 & 1.8 & 23 & 2.6 & 1.4 & 0.50[ & -0.33 & 1.33] & 8.62 \\
\hline Masao Nagayama 1994 & 17 & 2.7 & 0.8 & 37 & 1.9 & 0.5 & 0.80[ & 0.45 & $1.15]$ & 8.81 \\
\hline SatoshiKataoka 2000 & 58 & 4.3 & 0.3 & 32 & 2.8 & 0.2 & 1.50[ & 1.38 & $1.62]$ & 8.85 \\
\hline \multicolumn{7}{|c|}{ Heterogeneity: $\tau^{2}=0.49, \mathrm{I}^{2}=97.74 \%, \mathrm{H}^{2}=44.27$} & 0.82[ & 0.11 & $1.54]$ & \\
\hline \multicolumn{11}{|c|}{ Test of $\theta_{i}=\theta_{j}: Q(3)=132.81, p=0.00$} \\
\hline \multicolumn{7}{|l|}{ Overall } & 5.45[ & 3.97 & $6.93]$ & \\
\hline \multicolumn{11}{|c|}{ Heterogeneity: $\tau^{2}=6.45, \mathrm{I}^{2}=99.53 \%, \mathrm{H}^{2}=211.11$} \\
\hline \multicolumn{11}{|c|}{ Test of $\theta_{\mathrm{i}}=\theta_{\mathrm{j}}: \mathrm{Q}(11)=2322.22, \mathrm{p}=0.00$} \\
\hline \multicolumn{7}{|c|}{ Test of group differences: $\mathrm{Q}_{b}(2)=84.93, \mathrm{p}=0.00$} & & & & \\
\hline \multicolumn{7}{|c|}{ Random-effects DerSimonian-Laird model } & & & & \\
\hline
\end{tabular}

\section{Figure 3}

Plasma TAT levels in the acute phase of cardioembolic, lacunar and atherothrombotic strokes 


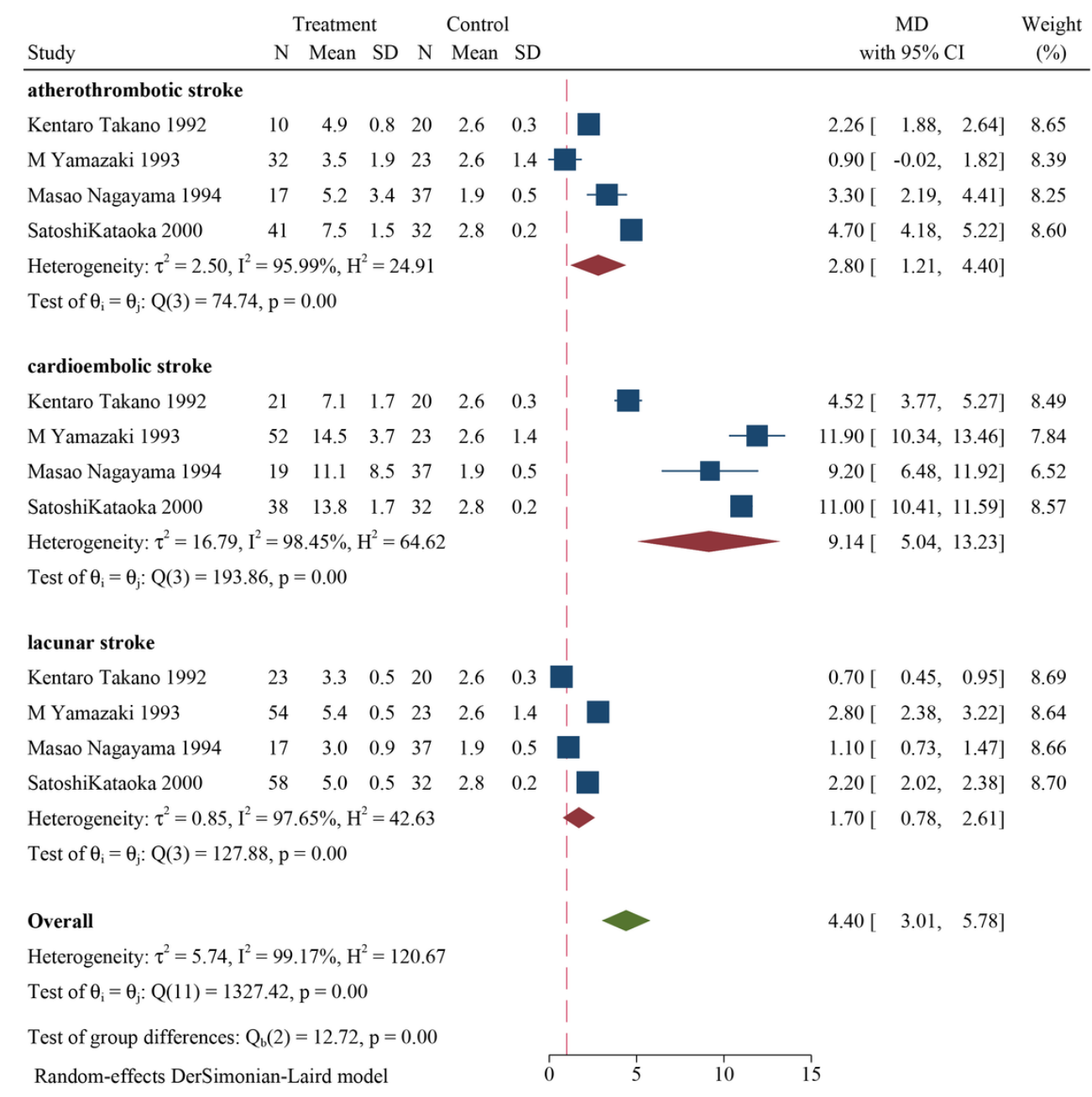

\section{Figure 4}

Plasma TAT levels in the subacute phase of cardioembolic, lacunar and atherothrombotic strokes 


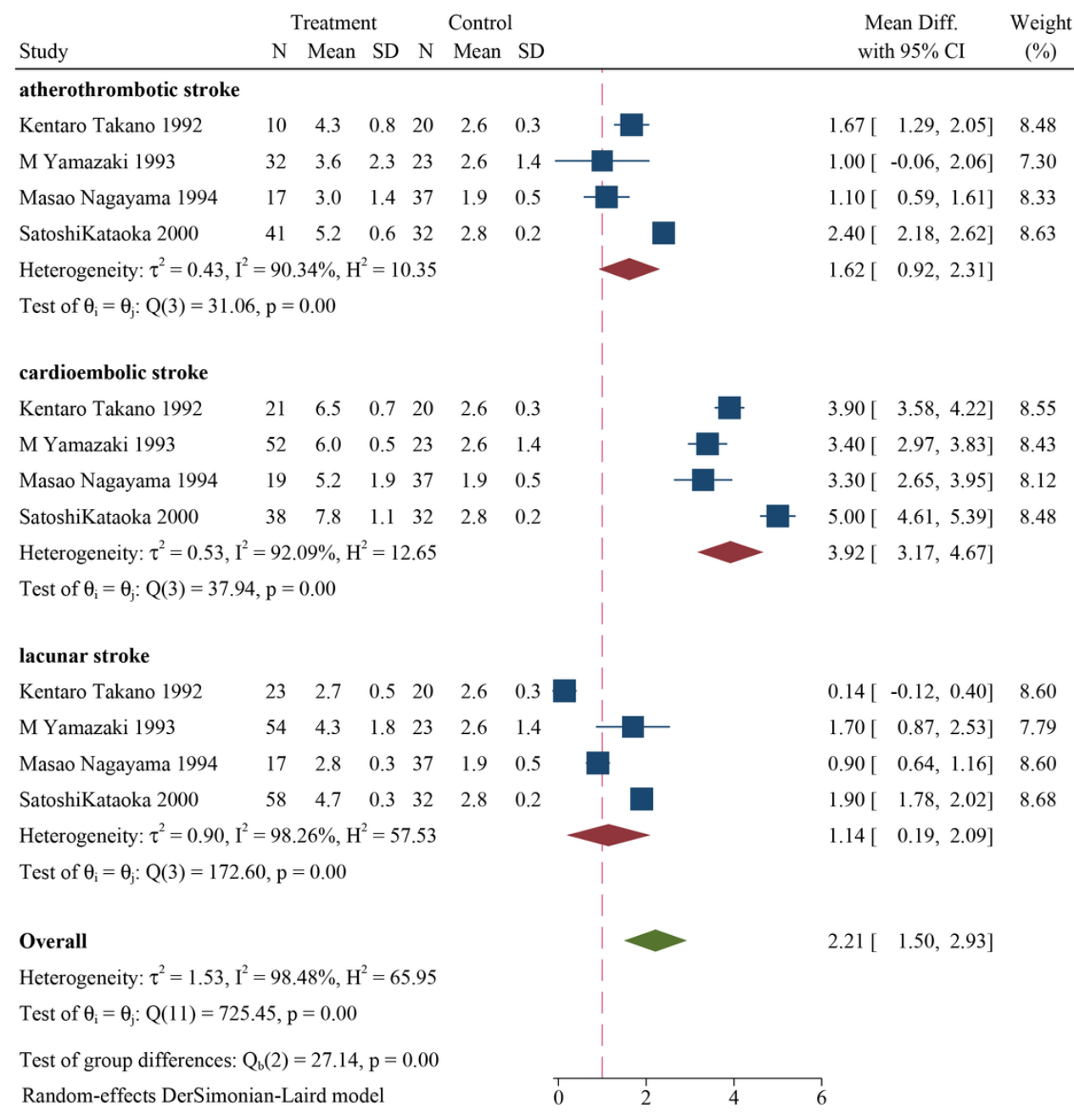

\section{Figure 5}

Plasma TAT levels in the chronic phase of cardioembolic, lacunar and atherothrombotic stroke

\section{Supplementary Files}

This is a list of supplementary files associated with this preprint. Click to download.

- PrismaChecklistforsystematicreviewsandmetaanalysis.pdf

- SupplementaryTable1.pdf

- SupplementaryTable2.pdf

- supplementaryFig1.pdf

- supplementaryFig2.pdf

- supplementaryFig3.pdf

- supplementaryFig4.pdf 